\title{
Mechanistic insight into a novel synthetic cantharidin analogue in a leukaemia model
}

\author{
STANTON HON LUNG KOK ${ }^{1}$, CHUNG HIN CHUI ${ }^{1,2}$, WING SZE LAM ${ }^{1}$, JIEN CHEN $^{1}$, \\ FUNG YI LAU ${ }^{2}$, RAYMOND SIU MING WONG ${ }^{2}$, GREGORY YIN MING CHENG ${ }^{2}$, WING KA TANG ${ }^{1}$, \\ CHOR HING CHENG ${ }^{1}$, JOHNNY CHEUK ON TANG ${ }^{1}$ and ALBERT SUN CHI CHAN ${ }^{1}$

\begin{abstract}
${ }^{1}$ Cancer Drug Research and Development Centre, Central Laboratory of the Institute of Molecular Technology for Drug Discovery and Synthesis, State Key Laboratory of Chinese Medicine and Molecular Pharmacology,

Department of Applied Biology and Chemical Technology, The Hong Kong Polytechnic University, Hung Hom; ${ }^{2}$ Department of Medicine and Therapeutics, Prince of Wales Hospital, The Chinese University of Hong Kong, Hong Kong, P.R. China
\end{abstract}

Received February 28, 2006; Accepted May 2, 2006

\begin{abstract}
Cantharidin isolated from Mylabris caraganae and other insects is used traditionally as an anti-cancer drug especially on hepatoma and leukaemia. Previously, we demonstrated that the novel synthetic cantharidin analogue CAN 032 possessed apoptotic activity on two human hepatoma cell lines Hep3B hepatocellular carcinoma and SKHep-1 liver adenocarcinoma. However, its underlying mechanistic action on cancer cells remained unclear. Herein, we furthered our work by making use of KG1a acute myelogenous leukaemia (AML) and K562 chronic myelogenous leukaemia (CML) as experimental models. As anticipated, both leukaemia cell lines were sensitive to the cytotoxic action of CAN 032. The activity of CAN 032 was both dose- and time-course-dependent. CAN 032 readily inhibited the colony formation potential of both leukaemia cell lines. KG1a AML treated with CAN032 decreased G1 phase cell population, mitochondrial membrane potential collapse, caspase 3 activation and hence DNA fragmentation. Pre-incubation of leukaemia cells with the general caspase inhibitor Z-VAD-FMK could partially reversed the apoptotic action of CAN 032. This result suggested that the caspasedependent pathway is necessary for the apoptotic action of CAN 032. CAN 032 provides a new direction for novel drug discovery in experimental cancer therapy.
\end{abstract}

Correspondence to: Dr Johnny Cheuk On Tang, Department of Applied Biology and Chemical Technology, The Hong Kong Polytechnic University, Hung Hom, Hong Kong, P.R. China

E-mail: bccotang@inet.polyu.edu.hk

Key words: cantharidin, caspase, leukaemia

\section{Introduction}

Cantharidin has been used clinically for treatment of cancer including hepatocellular carcinoma and leukaemia. It can be obtained from many types of insects including Mylabris caraganae. However, the highly toxic nature of cantharidin on the renal system and haematopoiesis limits its use (1-2).

Recently, we synthesized two cantharidin analogues (CAN 029 and CAN 030, respectively) and although both showed apoptotic induction ability on a variety of cancer cells, they were still relatively toxic towards non-malignant haematological disorder bone marrow (3). We have further synthesized another cantharidin analogue (CAN 032). The in vitro cytotoxicity of CAN 032 was screened using two hepatoma cell lines Hep3B and SK-Hep-1. CAN 032 showed a potential cytotoxic effect on these hepatoma cell lines similar to that of cantharidin. The toxicity test of these potential anti-tumour compounds was carried out using primary culture of non-malignant haematological bone marrow samples. Both the morphological investigation and the formation of DNA fragmentation were studied by inverted microscopy and DNA electrophoretic analysis (4). In the present study by employing the leukaemia cell lines $\mathrm{KG} 1 \mathrm{a}$ and $\mathrm{K} 562$, we further investigated its apoptotic pathway. Our results suggest that CAN 032 possesses cytotoxic activity on leukaemia cell lines including the reduction of $\mathrm{G}_{1}$ phase population and induction of genomic DNA fragmentation. Furthermore, mitochondrial membrane potential collapse and caspase 3 activation, were also stimulated. However, pre-incubation with the generic caspase inhibitor partially reversed CAN 032 induced cell death.

\section{Materials and methods}

Synthesis of CAN 032. Unless otherwise indicated, all reactions were carried out under nitrogen atmosphere. NMR spectra were recorded on a Varian $500 \mathrm{MHz}$ Fourier transform 

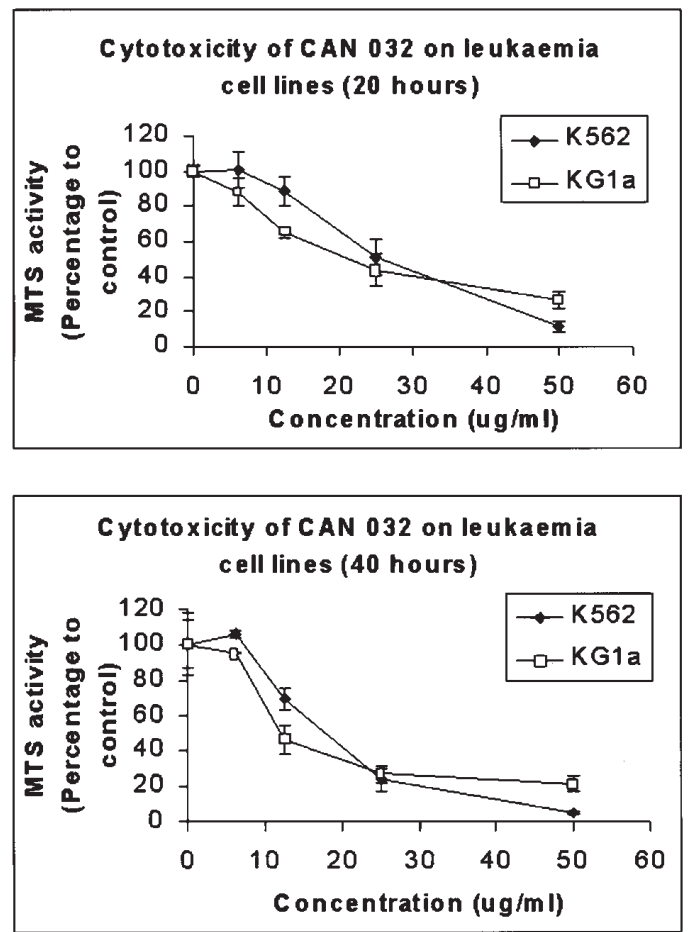

Figure 1. Cytotoxicity assay of CAN 032 on KG1a and K562 cell lines. Leukaemia cells were incubated with CAN 032 for $20 \mathrm{~h}$ (upper panel) and $40 \mathrm{~h}$ (lower panel) and then assayed respectively. Each experiment was done in triplicate. At least 3 independent experiments were done for each test. Results are representative of mean \pm SD. Similar results were obtained.

spectrometer. ${ }^{1} \mathrm{H}$ and ${ }^{13} \mathrm{C}\left\{{ }^{1} \mathrm{H}\right\}$ NMR spectra were recorded relative to residual protiated solvent; a positive value of the chemical shift denotes a resonance downfield from TMS. Mass analyses were performed on a Finnigan model Mat 95 ST mass spectrometer. Cantharidin and 2-amino-6-(trifluoromethoxy)-benzothiazole were purchased from Sigma-Aldrich. All other chemicals were purchased from commercial suppliers and were used without further purification. Toluene and triethylamine were freshly distilled from sodium under nitrogen. All reactions were monitored by analytical thinlayer chromatography (TLC) on Merck aluminum-precoated plates of silica gel 60 F254 with detection by spraying with $5 \%(\mathrm{w} / \mathrm{v})$ dodecamolybdophosphoric acid in ethanol or $5 \%$ $(\mathrm{w} / \mathrm{v})$ ninhydrin in ethanol and subsequent heating. Merck silica gel 60 (230-400 mesh) was used for flash chromatography.

A mixture of cantharidin (10 mg, $0.051 \mathrm{mmol}), 2$-amino6-(trifluoromethoxy)-benzothiazole (59.6 mg, $0.26 \mathrm{mmol}$ ), dried toluene and dried triethylamine $(4 \mathrm{ml} ; 2: 1, \mathrm{v} / \mathrm{v})$ in a sealed tube was heated for $2.5 \mathrm{~h}$ at $180^{\circ} \mathrm{C}$. Concentration followed by flash chromatograph yielded a product $(16 \mathrm{mg})$ of $76 \%$; ${ }^{1} \mathrm{H} \mathrm{NMR}\left(\mathrm{CDCl}_{3}, 500 \mathrm{MHz}\right): \delta 1.31$ (brs, $\left.6 \mathrm{H}\right), 1.75-$ $1.81(\mathrm{~m}, 2 \mathrm{H}), 1.87-1.91(\mathrm{~m}, 2 \mathrm{H}), 4.77-4.78(\mathrm{~m}, 2 \mathrm{H}) ; 7.36$ (dd, $J=8.5$ and $1 \mathrm{~Hz}, 1 \mathrm{H}), 7.76(\mathrm{~s}, 1 \mathrm{H}), 8.11(\mathrm{~d}, J=9.5 \mathrm{~Hz}$, $1 \mathrm{H}) ;{ }^{13} \mathrm{C} \mathrm{NMR}\left(\mathrm{CDCl}_{3}\right): \delta 13.0,23.8,54.3,84.5,113.7$, $119.4,120.4,124.5,146.7,147.5,152.7,178.0$; MS (ESI) $\mathrm{m} / \mathrm{z}(\%): 413\left(\mathrm{M}^{+}+1,100\right), 435(76)$.

Cell lines and cell culture. Two leukaemia cell lines including acute myelogenous leukaemia (AML) KG1a and chronic
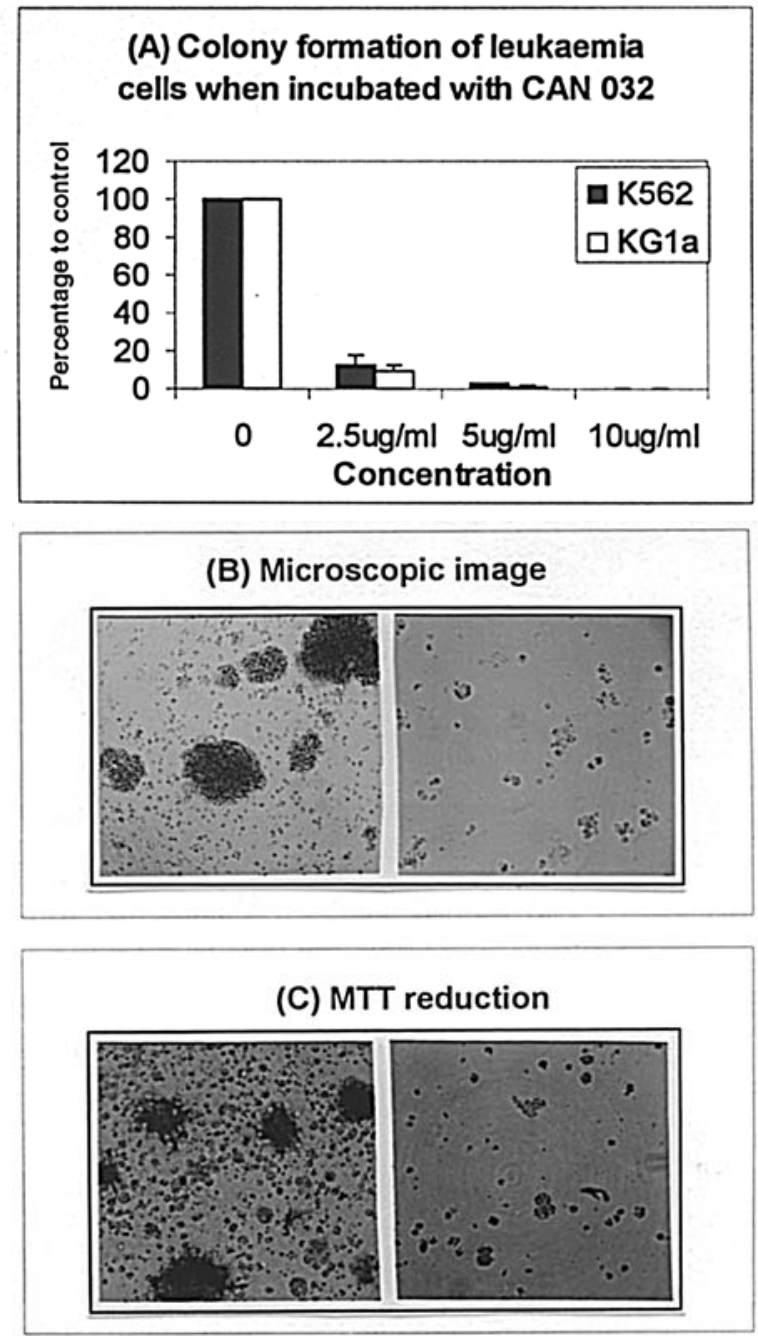

Figure 2. (A) Effects of CAN 032 on colony formation assay potential of KG1a and K562 leukaemia cells when incubated with various concentrations of CAN 032. (B) Colonies formed from KG1a cells when incubated with vehicle (left) and CAN 032. (C) Viable colonies were detected after further incubated with MTS/PMS. (Left: KG1a colonies treated with vehicle. Right: KG1a colonies treated with CAN 032).

myelogenous leukaemia (CML) K562 were obtained from American Type Culture Collection. Both leukaemia cell lines were maintained in RPMI-1640 medium (JRH Biosciences) supplemented with $10 \%$ of heat inactivated fetal bovine serum (Hyclone) together with antibiotics, penicillin and streptomycin. Cells were allowed to grow in a humidified cell culture incubator at $5 \%$ carbon dioxide.

Human bone marrow cell collection and isolation. Nonmalignant haematological disorder bone marrow cells were collected from consented patients by the bone marrow aspirate method. Two adult subjects were recruited (one male and one female). Immediately after collection, mono-nuclear cells were enriched by Ficoll Plaque (General Electricity, Amersham) gradient centrifugation. Cells were washed twice by phosphate-buffered saline and resuspended in complete medium. Viable cell percentage was then estimated by trypan blue exclusion assay and counted using a haemacytometer as described (5). 


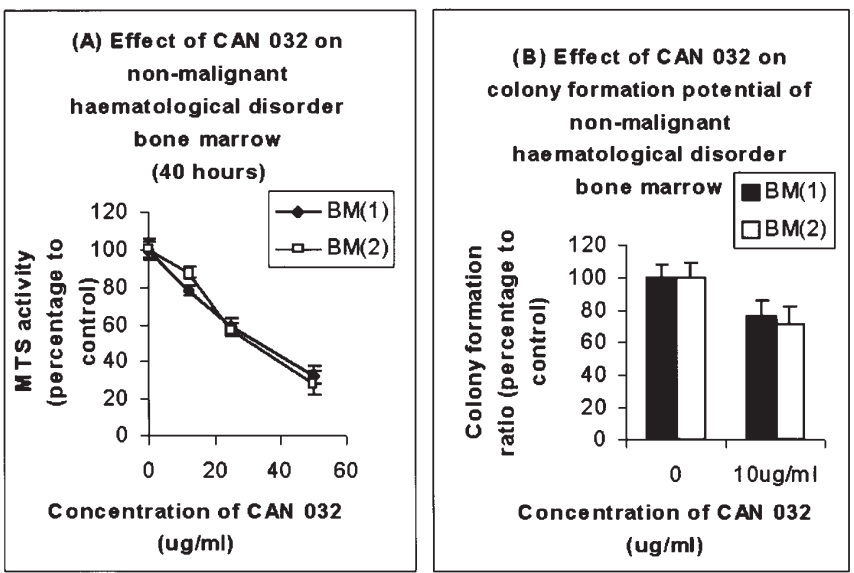

Figure 3. Toxicity test of CAN 032 on non-malignant haematological disorder bone marrow cells using (A) MTS/PMS assay and (B) colony formation assay.

[3-(4,5-dimethylthiazol-2-yl)-5-(3-carboxymethoxyphenyl)-2(4-sulfophenyl)-2H-tetrazolium] (MTS) assay. Changes in the cellular viability of CAN 032-treated cells were monitored using the MTS activity assay as reported previously $(6,7)$. Briefly, leukaemia cells (KG1a and K562) and bone marrow aspirate samples were seeded. After $6 \mathrm{~h}$, various compounds were added at different concentrations. After $20 \mathrm{~h}$ or $40 \mathrm{~h}$ of incubation, medium was removed and MTS/PMS solution was added and then incubated for a further $30 \mathrm{~min}$. Afterwards, optical absorbance was determined at $490 \mathrm{~nm}$ according to the user manual (Promega).

Morphological monitoring of CAN 032-treated colonies. Leukaemia cells or bone marrow cells were mixed with methylcellulose and incubated. Colony formation from CAN 032-treated leukaemia cells or bone marrow cells were recorded by investigation under an inverted microscope at the scheduled time point (8).

Cell cycle study. KG1a AML cells were either treated with vehicle $(0.01 \%$ DMSO) or $5 \mu \mathrm{g} / \mathrm{ml}$ of CAN 032 for $12 \mathrm{~h}$ and then stained with propidium iodide and analysed by using the Cell Quest software of a Becton Dickinson FACS flow cytometer (9).

Mitochondrial membrane potential depolarization. We used JC-1 as the detection probe (Molecular Probes) for the change of mitochondrial membrane potential. Briefly, after incubating KG1a AML cells with CAN 032 for $2 \mathrm{~h}$, they were stained with JC-1. Mitochondria have a high membrane potential would retain $\mathrm{JC}-1$ as $\mathrm{J}$-aggregate and give a red signal. When there is mitochondrial membrane potential depolarization, JC-1 is detached from the mitochondria and the signal shifts from red to green. Thus, a change in the green/red fluorescence intensity ratio from a low to a high value indicates that there is a collapse in mitochondrial membrane potential (10).

DNA fragmentation analysis. After treating KG1a cells with CAN $032(12.5 \mu \mathrm{g} / \mathrm{ml}$ for $20 \mathrm{~h})$, cells were fixed with $2 \%$ paraformaldehyde and then $70 \%$ ice cold ethanol. Then KG1a cells were incubated with TUNEL reaction mixture (Roche) and analysed by Becton Dickinson FACS scan flow cytometer using the Cell Quest software (11).

Caspase activity assay. To study whether caspase 3 protease activity was increased after $6 \mathrm{~h}$ of CAN 032 treatment of KG1a AML cells, we used a time resolved fluorescence technology-based caspase 3 activity kit purchased from Lance Perkin Elmer (Finland). Briefly, CAN 032-treated cells were washed with PBS and then total cellular protein extracts were prepared and quantitated by the Bradford method using bovine serum albumin as calibration. Afterwards, caspase 3 specific substrate and detection buffer were added to an equal amount of total cancer cell protein extract and individual caspase activity was analysed according to the instruction manuals provided. Finally, the resulting relative fluorescence units were compared with untreated control (12).

Caspase-dependency cytotoxicity assay. To determine whether CAN 032 mediated induction of apoptosis involved also caspase independent pathways, KG1a AML cells were pretreated with the caspase inhibitor Z-VAD-FMK, at a concentration of $20 \mu \mathrm{M}$. Following this, CAN 032 was added and cancer cells were further incubated for $40 \mathrm{~h}$. The resulting cellular viability was quantified using the MTS assay as described before (8).

\section{Results and Discussion}

Chemical synthesis of cantharidin analogue. We synthesized CAN 032 based on the principal chemical structure of the mother compound cantharidin. Details of the chemical reactions involved were reported (4). The CAN 032 was further dissolved in DMSO to a concentration of $50 \mathrm{mg} / \mathrm{ml}$ and a clear solution was obtained. It was stored in aliquot at $-20^{\circ} \mathrm{C}$. For the biological assay, the maximum concentration used was $25 \mu \mathrm{g} / \mathrm{ml}$, thus making the contribution of solvent always $<0.05 \%$.

CAN 032-induced leukaemia cell death is both time-courseand dose-dependent. Using MTS activity assay, we documented that the cytotoxicity of CAN 032 on KG1a and K562 leukaemia cells were both time-course and dosedependent (Fig. 1A and B, respectively).

Changes in the regeneration potential of leukaemia cells and bone marrow cells. To see whether CAN 032 could inhibit the colony formation potential of leukaemia cells, KG1a and K562 were incubated with CAN 032 and number of colonies formed were scored. As shown in Fig. 2A-C, CAN 032 significantly reduced the regeneration potential of KG1a and K562 cells in a dose-dependent manner. Since bone marrow suppression and gastrointestinal and urinary tract toxicity are still important side effects of cantharidin, we further tested the toxicity of CAN 032 on non-malignant haematological bone marrow samples using both MTS activity assay and colony formation assay. As shown in Fig. 3A and B, the toxicity of CAN 032 was lower on non-malignant haematological disordered bone marrow than that of leukaemia cell lines. 

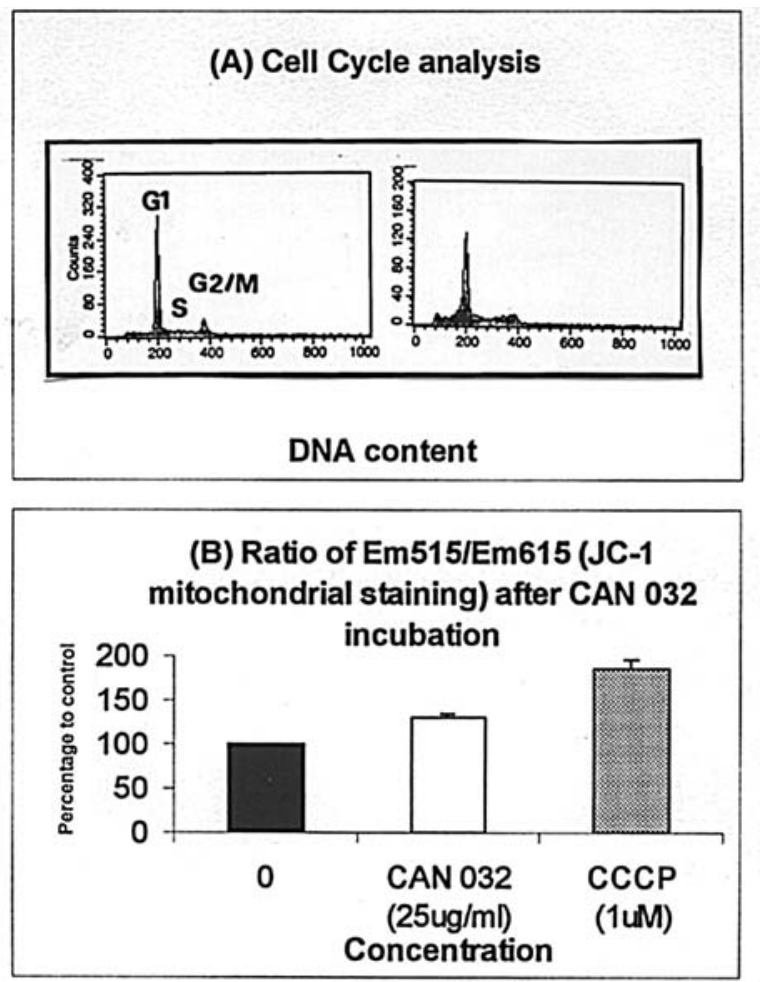

Figure 4. (A) Cell cycle study for the effect of CAN $032(5 \mu \mathrm{g} / \mathrm{ml}$ for $12 \mathrm{~h})$ on KG1a cells (right) when compared with vehicle $(0.01 \%$ DMSO, left). (B) CAN 032 induced mitochondrial membrane potential depolarization in AML KG1a cells after staining with the JC-1 probe. An increment of emission $515 \mathrm{~nm}$ to emission 615 after an excitation at $485 \mathrm{~nm}$ indicated that there was a collapse in mitochondrial membrane potential. CCCP is an ionophore able to cause dissipation of the proton gradient built-up on the inner mitochondrial membrane and was used as a positive control.

Changes in cell cycle distribution, mitochondrial membrane potential collapse and genomic DNA fragmenation of leukaemia cells resulted from incubation with CAN 032. Recently, our experimental data demonstrated that CAN 032 significantly reduced the G1 phase population of Hep3B HCC cells. Herein, a similar observation was detected using KG1a leukaemia cells (Fig. 4A). Mitochondrial membrane potential depolarization was also proven using the JC-1 probe staining method (Fig. 4B). As anticipated, induction of genomic DNA laddering was recruited using the TUNEL assay (Fig. 5A). These experimental data suggest that the cytotoxic nature of CAN 032 on leukaemia cells is very close to that of hepatoma cells in vitro (4).

Is caspase necessary for the activity of CAN 032? To our knowledge, some cantharidin related compounds such as the norcantharidin needs the activation of caspase 3 for its biological action. Herein we showed that caspase 3 activation also participated in CAN 032 induced KG1a cell death (Fig. 5B). When we pre-incubated KG1a with the generic caspase inhibitior Z-VAD-FMK before adding CAN 032, this resulted in partial reversal of the apoptotic action of CAN 032 (Fig. 5C). Our data therefore suggest that caspasedependent pathway is necessary for the cell death stimulation of CAN 032.

Recently, it was described that cantharidin-induced leukaemia cell death is p53-dependent in leukaemia cell lines
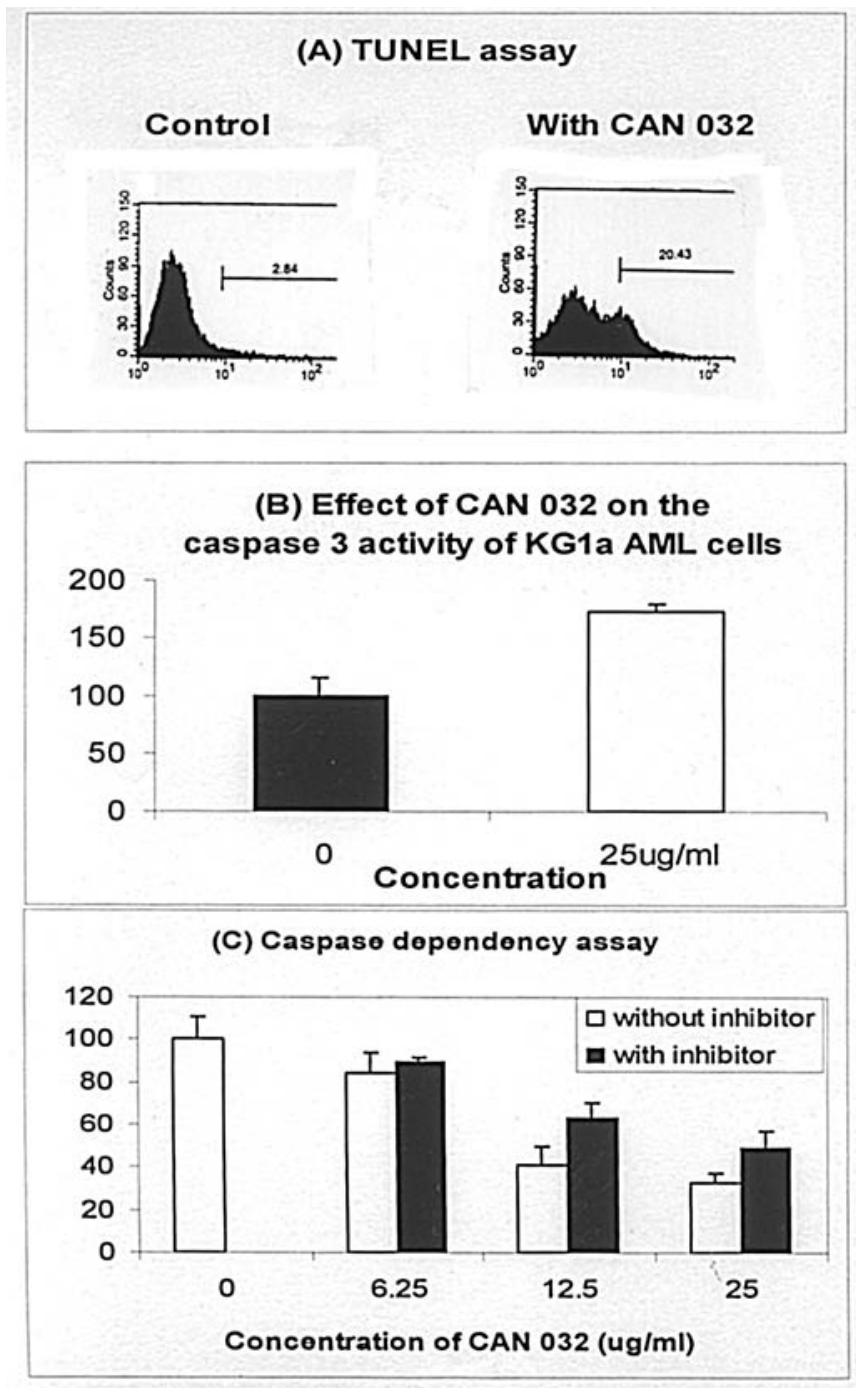

Figure 5. (A) TUNEL analysis illustrates that genomic DNA fragmentation is involved in the activity of CAN 032 on KGla cells $(12.5 \mu \mathrm{g} / \mathrm{ml}$ for $20 \mathrm{~h}$ ). (B) Activity of caspase 3 on CAN 032-treated KG1a cells after a $6 \mathrm{~h}$ incubation. Results represent the average \pm SD of triplicate tests from one experiment, representative of three independent experiments, leading to similar results. (C) Cytotoxicity assay on CAN 032-treated KG1a cells after a $40 \mathrm{~h}$ incubation in the absence or presence of the caspase inhibitor $\mathrm{Z}$ VAD-FMK (indicated as 'I'). Each experiment was done in triplicate. Results represent the average \pm SD of three independent experiments. For both (B) and (C), results are expressed as 'percentage to untreated control'.

(13). Previously, our investigation into the cytotoxicity of CAN 032 on hepatoma cell lines Hep3B and SK-Hep-1 suggested that the anti-cancer potential of CAN 032 is most likely p53-independent (4). Currently, we are modifying the structure of CAN 032 in order to further improve its solubility (we named the compound CAN 039) so that its absorption efficiency in the gastrointestinal system could be improved when it is tested orally in animal model in vivo (Kok et al, unpublished data).

In conclusion, we believe that the accumulation of experimental evidence could further sustain the scientific base for the possible clinical use of cantharidin-related analogues in the future. CAN 032 provides a new direction for novel drug discovery in experimental cancer therapy. 


\section{Acknowledgements}

We acknowledge the support by the Area of Strategic Development (ASD) programme of the Hong Kong Polytechnic University (H.K.P.U.) (work programme A012). This study was supported by the Areas of Excellence Scheme established under the University Grants Committee of the Hong Kong Special Administrative Region, China (Project No. AoE/P-10/01) and a Niche Area Grant offered by the H.K.P.U. Drs F.Y. Lau and C.H. Chui are the honourary tutors kindly offered by Professors J.J.Y. Sung and G.Y.M. Cheng from Department of Medicine and Therapeutics, Prince of Wales Hospital, The Chinese University of Hong Kong. Dr S.H.L. Kok is supported by the post of 'Research Fellow' kindly offered by Professor A.S.C. Chan. Dr S.H.L.K. would like to thank Dr C.H.C. who gave us valuable advice on the anti-cancer drug screening experiments. Dr C.H. Chui would like to thank Professors A.S.C. Chan, K.Y. Wong, C.P. Lau, S.C.L. Lo and J.C.O. Tang who provided the opportunity to Dr C.H. Chui to be the 'Scientific Officer' in the Department of Applied Biology and Chemical Technology, H.K.P.U.

\section{References}

1. Tsauer W, Lin JG, Lin PY, Hsu FL and Chiang HC: The effects of cantharidin analogues on xanthine oxidase. Anticancer Res 17: 2095-2098, 1997.

2. Zhang S: A study on antitumor chemotherapeutic agents: synthesis of N-cantharidine derivatives. Yao Xue Xue Bao 16: 784-786, 1981.

3. Kok SHL, Chui CH, Lam WS, Chen J, Tang JCO, Lau FY, Cheng GYM, Wong RSM and Chan ASC: Induction of apoptosis on carcinoma cells by two synthetic cantharidin analogues. Int $\mathbf{J}$ Mol Med 17: 151-157, 2006.

4. Kok SHL, Chui CH, Lam WS, Chen J, Tang JCO, Lau FY, Cheng GYM, Wong RSM, Lai PPS, Leung TWT and Chan ASC: Apoptotic activity of a novel synthetic cantharidin analogue on hepatoma cell lines. Int J Mol Med 17: 945-949, 2006.
5. Lau FY, Chui CH, Gambari R, Kok SHL, Kan KL, Cheng GYM, Wong RSM, Teo ITN, Cheng CH, Wan TSK, Chan ASC and Tang JCO: Antiproliferative and apoptosis-inducing activity of Brucea javanica extract on human carcinoma cells. Int J Mol Med 16: 1157-1162, 2005.

6. Cheung F, Chui CH, Chan ASC, Lau FY, Cheng GYM, Wong RSM, Kok SHL, Teo ITN, Cheng CH and Tang JCO: Inhibition of proteasome activity in Gleditsia sinensis fruit extract-mediated apoptosis on human carcinoma cells. Int J Mol Med 16: 925-929, 2005.

7. Teo ITN, Chui CH, Tang JCO, Lau FY, Cheng GYM, Wong RSM, Kok SHL, Cheng CH, Chan ASC and Ho KP: Antiproliferation and induction of cell death of Phaffia rhodozyma extract fermented by brewer malt waste on breast cancer cells. Int J Mol Med 16: 931-936, 2005.

8. Chui CH, Gambari R, Lau FY, Cheng GYM, Wong RSM, Kok SHL, Tang JCO, Teo ITN, Cheung F, Cheng CH, Ho KP, Chan ASC and Wong A: In vitro anti-cancer activity of a novel microbial fermentation product on human carcinomas. Int J Mol Med 17: 675-679, 2006.

9. Chui CH, Hau DKP, Lau FY, Cheng GYM, Wong RSM, Gambari R, Kok SHL, Lai KB, Teo ITN, Leung TWT, Higa T, Ke B, Tang JCO, Fong DWF and Chan ASC: Apoptotic potential of the concentrated effective microorganism fermentation extract on human cancer cells. Int J Mol Med 17: 279-284, 2006.

10. Chui CH, Lau FY, Chan ASC, Cheng GYM, Wong RSM, Lai KB, Kok SHL, Au Yeung TTL, Teo ITN, Yau MYC, Cheung F, Cheng $\mathrm{CH}$ and Tang JCO: Gleditsia sinensis fruit extract-induced apoptosis involves changes of reactive oxygen species level, mitochondrial membrane depolarization and caspase 3 activation. Int J Mol Med 15: 539-543, 2005.

11. Chow LMC, Tang JCO, Teo ITN, Chui CH, Lau FY, Cheng G, Leung TWT, Wong RSM, Wong ILK, Tsang KMS, Tan WQ, Zhao YZ, Lai KB, Lam WH, Guo DA and Chan ASC: Antiproliferative activity of the extract of Gleditsia sinensis fruit on human solid tumour cell lines. Chemotherapy 48: 303-308, 2002.

12. Chui CH, Lau FY, Tang JCO, Kam KL, Cheng GYM, Wong RSM, Kok SHL, Lai PBS, Ho R, Gambari R and Chan ASC: Activities of fresh juice of Scutellaria barbata and warmed water extract of Radix Sophorae Tonkinensis on antiproliferation and apoptosis of human cancer cell lines. Int J Mol Med 16: 337-341, 2005.

13. Efferth T, Rauh R, Kahl S, Tomicic M, Bochzelt H, Tome ME, Briehl MM, Bauer R and Kaina B: Molecular modes of action of cantharidin in tumor cells. Biochem Pharmacol 69: 811-818, 2005 . 